\title{
Diálogos entre a Capoeira e a Museologia Social
}

Suzy da Silva Santos ${ }^{1}$

Roseane Maria da Silva ${ }^{2}$

Compreendidos como uma das mais importantes expressões da cultura, os museus possuem tradicionalmente a função de colecionar/guardar, preservar, conservar, pesquisar e exibir parte dos testemunhos históricos, científicos, artísticos e culturais significativos para a humanidade. A partir de meados do século XX a essas funções agregaram-se outras, comprometidas com questões

${ }^{1}$ Professora e Pesquisadora. Possui Graduação em História - DH-FLLCH (2014) e Mestrado em Museologia - PPGMUS (2017) pela Universidade de São Paulo (USP). Durante a Graduação desenvolveu a Pesquisa de Iniciação Científica "Ecomuseus e Museus Comunitários: Possibilidades de Salvaguarda da Memória Popular" (20132014) e na Pós-Graduação a Pesquisa "Ecomuseus e Museus Comunitários no Brasil: Estudo Exploratório de Novas Possibilidades Museológicas" (2015-2017). Possui experiência como Consultora em Pesquisas, Documentalista, Técnica em Museus e Arquivos, Professora e Arte-Educadora, com cerca de 10 anos de experiência em setores públicos e privados. Tem se especializado nas áreas de História Social e Museologia Social, e participado de Encontros, Simpósios e Seminários relacionados a Museus, Museologia, Patrimônio, Curadoria Colaborativa, Cultura Popular, Diversidade Cultural etc.

suzy.santos@yahoo.com.br

2 Roseane Maria da Silva ou Professora Nega Tana: Capoeirista (Grupo Capoeira E.C.E Brasil), Professora e Educadora Social. É Licenciada em Educação Física pela Universidade Cruzeiro do Sul e atualmente cursa o Bacharelado em Educação Física na mesma instituição.

roseanecapoeira@hotmail.com 
contemporâneas aos museus, a partir de autocríticas, reflexões e contestações levantadas principalmente por profissionais de museus que se identificaram e integraram o movimento museológico denominado Nova Museologia.

Influenciados/as pelos movimentos europeus de contracultura dos anos 1960 e por processos de lutas, movimentos de contestação e transformações em diversas partes do globo, que passaram a questionar as estruturas da sociedade, assim como as noções de progresso e evolução (amplamente disseminadas no século XIX), a exigir a real democratização das instituições políticas, educacionais, culturais etc., a partir de uma perspectiva participativa, esses profissionais sentiram-se pressionados a refletir e questionar a relação das instituições museológicas com os contextos sociais em que estavam inseridas, os métodos e técnicas empregadas e também seu aparato conceitual. A partir de então, preconiza-se a mudança da base de organização das instituições museológicas das coleções para as funções sociais, dos edifícios para os territórios e de um público visitante e contemplativo para um público participativo, cujos níveis participação variam de acordo com as instituições. Finalmente, preconiza-se um museu integrado à sociedade, que deveria orientar-se para o desenvolvimento comunitário, ter consciência dos problemas enfrentados pelas comunidades e intervir socialmente, contribuindo para a resolução desses problemas.

O campo museológico como um todo sofreu o impacto e a influência das reflexões impulsionadas pelo movimento da Nova Museologia, e vivencia, pouco a pouco, processos de avanços e rupturas nas instituições museológicas e no pensamento museal. No Brasil, é possível observar repercussões desse movimento principalmente a partir da década de 1980, com a redemocratização do país.

Além da renovação de caráter técnico e museográfico, aos museus já consolidados são propostas inovações teóricas (museológicas) e na mentalidade de seus profissionais, de quem se cobra uma postura crítica diante dos problemas da sociedade. Paralelamente, 
surgem outros museus, de base comunitária, denominados em sua maioria como ecomuseus e museus comunitários, mas também com outras nomenclaturas criativas. Esses museus localizam-se por toda a parte, em áreas urbanas, rurais, industriais, em regiões centrais e periféricas e envolvem classes e grupos sociais diversos, que reconhecem seu patrimônio como ferramenta importante para o desenvolvimento comunitário.

Nos ecomuseus e museus comunitários é desenvolvida uma museologia popular, ativa, criativa, comunitária e participativa (RIVARD, 1984). Neles, a Nova Museologia se expressa não apenas como um fazer museológico "para o público", mas um fazer museológico “para e com o público” (BELLAIGUE, 1993, p.74-77). Neles, os grupos considerados minorias (mulheres, negros etc.), excluídos dos espaços museológicos históricamente, onde as culturas dominantes das elites eram as valorizadas, onde se legitimava o mito da homogeneidade cultural (MAURE apud ALONSO FERNÁNDEZ, 1999, p.73-148) e se legitimava uma História Oficial considerada única e verdadeira.

\section{Museologia Social e a construção de uma Museologia Afro- brasileira}

Mario Moutinho (1995, p.22-23) afirma que a Museologia Social é uma museologia do cotidiano, ou museologia informal, sem recursos financeiros ou saberes sofisticados, formada por iniciativas ou processos museológicos que podem ser permanentes ou intermitentes, conservadores, reprodutores de modelos préexistentes ou criativos. No entanto, ao mesmo tempo em que afirma que a Museologia Social compõe um quadro formado por diferentes formas de museologia, afirma que esta "nova museologia" não é um fenômeno de ruptura e não se estrutura à margem da museologia tradicional e urbana, mas trata-se de uma mudança que integra o saber museológico acumulado ao longo de várias gerações.

Para Chagas e Gouveia (2014, p.16), Museologia Social é um neologismo que se fortaleceu a partir da década de 1990, com a 
perda de potência da expressão Nova Museologia. Indica uma museologia popular, ativa, crítica, engajada e dialógica, com compromissos políticos claros, como: a redução das injustiças e desigualdades sociais, o combate a preconceitos, a melhoria da qualidade de vida coletiva, o fortalecimento da dignidade e da coesão social, a utilização do poder da memória, do patrimônio e do museu em favor das comunidades populares, dos povos indígenas e quilombolas e dos movimentos sociais.

No âmbito da Museologia Social outras museologias afirmativas, como a Museologia de Gênero, a Museologia LGBT e a Museologia Indígena. São estas museologias afirmativas, referentes a grupos específicos, que evidenciam os lugares de ação e fala em primeira pessoa. Não sei trata apenas de representatividade, mas de representação e protagonismo.

Pensar em uma Museologia Afro-brasileira é atribuir uma perspectiva racial para as experiências e o conhecimento museológico, problematizando a presença (ou ausência) negra nos museus, do corpo de funcionários ${ }^{3}$ ao público visitante e/ou atuante (no caso dos museus comunitários), dos acervos aos projetos expográficos e, finalmente, dos discursos presentes nestas instituições.

Ao analisar a representação das mulheres negras nas exposições de alguns museus da cidade de Salvador/BA, a professora e museóloga Joana Flores Silva $(2015$, p.14) constata que as "representatividades encontram-se sempre atreladas à figura estereotipada da mulher escravizada"4 ou através de seus corpos, utilizados "como suportes expositivos para os objetos fetiches" (idem, p.27). Silva (2015, p.17)

${ }^{3}$ Com exceção aos profissionais contratados para a segurança dos museus, geralmente de empresas terceiradas.

${ }^{4}$ Quase sempre associada ao estereótipo da mãe preta, sem nome, filiação ou status social - reflexão compartilhada por Joana Flores na palestra "Memórias e Narrativas das Mulheres Negras nos Museus: Silêncio ou Esquecimento?", que compôs o ciclo de palestras "Memória e Esquecimento nos Museus", promovido pelo SESC-SP em julho de 2016. 
conclui que a memória das mulheres negras "ainda não foi retirada dos 'porões'".

A utilização do corpo negro como elemento central de atividades museológicas no transcorrer dos séculos (XIX e XX) foi discutida pelo professor e museólogo brasileiro Marcelo Nascimento Bernardo da Cunha, na palestra "Memórias e Estigmas: Museus e a Objetivação do Corpo Negro em Exposições" ${ }^{5}$. Cunha recordou os Zoológicos Humanos, fenômeno de massa que compôs as Exposições Universais do século XIX, utilizadas pelas potências coloniais do período para demonstrar seu poderio, justificar a ação colonizadora e o empreendedorismo que acreditavam (ou não) messiânico. Nos Zoológicos Humanos povos não-europeus eram animalizados a partir de espetáculos ou apenas para a observação de um cotidiano forjado. Enfatizou ainda como a utilização desses corpos serviu de fomento às teorias raciais, com a agregação de valores negativos ao corpo negro (cabelo, cor da pele etc.), que era exibido sem censura, e aos poucos passou por um processo de deserotização à exotização, mantida até os dias atuais, como podem ser notados em alguns anúncios publicitários, e também em alguns museus de Arte e/ou História, que ao expor as obras artísticas em referência a estes povos, geralmente não se preocupam em desconstruir os estereótipos, quer pela falta de conhecimento, sensibilidade ou mesmo interesse.

Uma exceção é observada nos Memoriais criados para "homenagear figuras representativas de um grupo político, religioso, ou mesmo uma personalidade de grande veiculação midiática no cenário cultural da Cidade" (SILVA, 2015, p.26), como podemos observar nos Museus e Memoriais em llês e Terreiros de Candomblé e Umbanda, criados com o objetivo de preservar as memórias dos terreiros e homenagear Yalorixás e Babalorixás ${ }^{6}$,

${ }^{5}$ Que compôs o ciclo de palestras "Memória e Esquecimento nos Museus", promovido pelo SESC-SP em julho de 2016.

${ }^{6}$ Mães e Pais de Santo. 
entre outras personalidades importantes para as "comunidadesterreiros" (GAMA, 2015).

\section{Diásporas africanas e suas consequências}

Durante o Brasil Colonial, povos nativos americanos e africanos foram utilizados como mão-de-obra escravizada nos trabalhos desenvolvidos nos engenhos do Brasil Colonial. A passagem da escravidão do índio para o negro variou no tempo e no espaço, e as principais razão para que ocorresse foram: os povos indígenas tinham uma cultura incompatível com o trabalho intensivo, regular e compulsório, e resistiram às diversas formas de sujeição, por meio da guerra, da fuga e da recusa ao trabalho compulsório. E as epidemias produzidas pelo contato com os brancos foram responsáveis pela dizimação de milhares deles.

Desde o século $\mathrm{XV}$, quando os portugueses começaram a percorrer a costa da África, haviam iniciado o tráfico de africanos, e nas últimas décadas do século XVI, o comércio negreiro já estava dando muitos lucros. A partir da década de 1570 a Coroa Portuguesa incentivou a importação de africanos escravizados, ciente de sua habilidade com trabalhos agrícolas, além disso algumas culturas desenvolviam usualmente trabalhos com ferro e criavam gados. Os povos do "continente negro" dividiam-se em "dois grandes ramos étnicos: os sudaneses, predominantes na África ocidental, Sudão egípcio e na costa norte do Golfo da Guiné, e os bantos, da África equatorial e tropical, de parte do Golfo da Guiné, do Congo, Angola e Moçambique. Essa grande divisão não nos deve levar a esquecer que os negros escravizados no Brasil provinham de muitas tribos ou reinos, com suas culturas próprios. Por exemplo: os iorubas, jejes, tapaz, hauçás, entre os sudaneses; e os angolas, bengalas, monjolos, moçambiques, entre os bantos" (FAUSTO, 2009, p.51).

No contexto de escravidão, esses povos sofreram diversos tipos de restrição e opressão. Eram proibidos de manter e manifestar suas culturas originárias, hábitos, religiosidades, idiomas etc., além da proibição do mantenimento de suas organizações sociais e/ou familiares tradicionais. Afinal, à vista dos comerciantes de povos escravizados e senhores de engenho haviam perdido sua 
humanidade, passando por um processo de objetificação. No entanto, as medidas opressoras não foram suficientes para a escravização dos corpos, mentes e vidas desses povos. Aos poucos, novos laços se firmavam, até mesmo entre povos de origens distintas, e algumas formas de resistência se estruturaram.

Os primeiros documentos de referência da Capoeira referem-se ao século XIX, mas a tradição oral transmitida por mestres/as remete a datas mais longínquas. Um consenso é que sua origem á africana, mas consolidou-se no território brasileiro.

O termo Capoeira é de origem etnolinguística tupi-guarani kapu'era: o que foi mata, ou mata rasteira - ka'a: mata / pûera: o que foi (FERREIRA, 1986, p.344; NAVARRO, 2013). Especula-se que os povos indígenas não apenas contribuíram com 0 desenvolvimento deste "jogo-luta" (LUSSAC, 2015, p.267), mas que foram responsáveis por sua criação. Assim, podemos considerar a Capoeira como uma tradição cultural afro-brasileira ou ainda como uma tradição cultural-afro-indígena-brasileira ${ }^{7}$.

A prática da Capoeira ocorria nos terreiros que cercavam as grandes propriedades rurais de base escravocrata, próximos às senzalas, em campos com pequenos arbustos, chamados à época como Capoeira ou Capoeirão.

Os povos de origem banto foram os que mais se distinguiram na prática da Capoeira. "No cativeiro, os negros disfarçavam a suposta luta em dança com a introdução de instrumentos musicais e movimentos cadenciados para não levantar suspeitas" (YRAPURU DZ, 2014, p.10). O disfarçe era necessário devido à proibição que os negros tinham de praticar qualquer tipo de luta.

Para Edison Carneiro (apud YRAPURU DZ, 2014, p.10), "inicialmente a Capoeira era praticada entre os negros angolas, não como instrumento de defesa, mas como dança religiosa". No entanto, serviu como meio de defesa pessoal em momentos em que os maus

${ }^{7}$ Comunicação oral: assim defendida pelo Mestre Dinho Caruaru, liderança do grupo Capoeira E.C.E. Brasil - Associação Cultural Escola de Contos Étnicos do Brasil (Guarulhos/SP). 
tratos aos negros escravizados se agravaram. Há diversos relatos sobre as formas de resistência à escravidão por parte dos negros, por meio de fugas individuais ou em massa, agressões contra senhores e resistências cotidianas, e certamente a Capoeira esteve presente nesses diversos momentos de opressão e resistência. Ao refugiarem-se nas matas, clareiras ou capoeiras, enfrentavam feitores ou capitães-do-mato que os perseguiam e tentavam capturá-los novamente. Diziam eles aos senhores de engenho: "Ele me pegou na capoeira!” (REGO apud YRAPURU DZ, 2014, p.11). Já nos quilombos a prática de Capoeira era livre e necessária para a defesa desses locais de refúgio criados por negros que escapavam à escravidão e onde recompunham formas de organização social semelhantes às africanas (FAUSTO, 2009, p.52).

O uso da Capoeira como forma de resistência contribuiu com a construção de uma imagem negativa sobre ela, considerada perigosa, agressiva, praticada por delinquentes, marginais, vadios, malandros e foras da $\mathrm{lei}^{8}$, "que a sociedade deveria vigiar e as leis deveriam enquadrar e punir" (YRAPURU DZ, 2014, p.68), e a relegou à marginalidade. Eram considerados pelo Código Criminal do Império do Brasil de 1830, o primeiro código penal da nova nação, como vadios, enquadrados no capítulo IV, artigo 295. Já o Código Penal de 1890 deu-Ihes um tratamento específico, no capítuloXIII, intitulado "Dos vadios e capoeiras", base para a perseguição e proibição de indivíduos e grupos.

Por conta dessas perseguições, diversas denominações foram atribuídas à Capoeira, como frevo (Recife), pernada carioca (Rio de Janeiro), tiririca (São Paulo), brincadeira-de-nego, brincadeira-deangola e dança-da-malandragem (Bahia).

De acordo com Yrapuru Dz (2014, p.9), os mestres de Capoeira do tempo do cativeiro não transmitiram às gerações seguintes um conjunto de mitos, rezas e cantigas em língua africana. Os primeiros

${ }^{8} \mathrm{O}$ sistema escravocrata funcionou de forma legal juridicamente até 13 de maio de 1888, com a assinatura da Lei Áurea pela Princesa Isabel, após muita pressão dos negros escravizados e libertos, além de brancos simpatizantes à causa. 
registros escritos tampouco dão detalhes sobre o que nela se cantava. É muito provável que os capoeiristas tenham adotado rapidamente o português para facilitar a comunicação".

Apesar da criminalização, em 1889 surgiu no Rio de Janeiro a Capoeira Desportiva, "resultante do reaproveitamento da expressão da antiga capoeiragem em seus gestos e movimentos para a construção de um método ginástico caracterizado por uma forma de luta sistematizada" (PORTO apud YRAPURU DZ, 2014, p.95), e nas primeiras décadas do século XX a Capoeira atraiu muitos intelectuais, escritores, jornalistas e boêmios.

Na década de 1930, a Capoeira passa por algumas transformações importantes. A principal delas foi a criação da Capoeira Regional, inicialmente denominada Luta Regional Baiana, por Manoel dos Reis Machado, ou Mestre Bimba. Seu intuito era criar um "jogo de ataque e defesa mesclado à um exercício espiritual e mental" (FACURY, 2015), modernizando o jogo, agregando novas técnicas, golpes, maior agilidade novos instrumentos e um sistema de graduação (Batizado, Formatura e Especialização). "A roda se torna uma manifestação de combate fundido ao teor ritualístico e formalizado" (FACURY, 2015).

Sentindo a necessidade de ressaltar e preservar a herança cultural deixada pelos ancestrais africanos, alguns mestres passaram a chamar como Capoeira Angola a prática de Capoeira que não passou por estas transformações, o principal deles foi Vicente Ferreira Pastinha, o Mestre Pastinha. Diferentemente da Capoeira Regional, a Capoeira Angola compunha-se de um ritmo musical lento, golpes cadenciados e mais próximos ao solo e muita mandinga (malícia de jogo), tornando o jogo mais fraterno e folclórico, mas a malícia do jogo sugere que não haja vacilo, pois um golpe certeiro pode desconcertar o capoeirista distraído. Pela grande contribuição que deram à Capoeira, Mestre Bimba foi considerado patrono da Capoeira no Brasil e Mestre Pastinha o maior representante da Capoeira Angola.

Neste momento histórico o então presidente Getúlio Vargas desenvolveu um projeto nacionalista com o intuito de promover a 
valorização da cultura nacional e a ressignificação das manifestações culturais brasileiras. Aproveitando este contexto e também a ascensão das lutas marciais no Brasil, Mestre Bimba apresentou a Capoeira para Vargas e em 1934 o decreto-lei que proibia a prática da Capoeira e outras manifestações e cultos afrobrasileiros foi extinto pelo presidente. A partir de então a capoeira foi elevada à categoria de "esporte nacional brasileiro". No entanto, por falta de apoio dos poderes públicos, a Capoeira como manifestação cultural afro-brasileira continuou sem o respeito merecido e ainda hoje existe grande demanda por seu reconhecimento, valorização e promoção.

A partir da década de 1970 surge a chamada Capoeira Contemporânea, um estilo misto desenvolvido por alguns grupos que uniam as principais características da Capoeira Regional e da Capoeira Angola. Pode também incluir acrobacias e outros arranjos. A Capoeira Contemporânea foi considerada tanto uma evolução natural da capoeira, como uma descaracterização, ou até mesmo má-interpretação das tradições capoeirísticas (MESTRE VALDEMAR [...], 2013).

"A normatização, uniformização, adoção do sistema de graduação através de cordas ou cordões e a fundação de Federações e Associações congregando os grupos são outras características importantes do processo de institucionalização da capoeira como esporte, consagrando o novo estilo" (IPHAN, 2008, p.12).

A Capoeira tem múltiplas faces, é arte, dança, luta, jogo, esporte e uma das mais expressivas manifestações culturais afro-brasileiras (uma das consequências da diáspora africana) e também um dos mais expressivos símbolos da cultura brasileira. Para Mestre Pastinha (apud YRAPURU DZ, 2014, p.114), a Capoeira é “[...] mandinga de escravo em ânsia de liberdade; seu princípio foi sem métodos; mas o seu fim é inconcebível ao mais sábio dos mestres". Em julho de 2008, por iniciativa do Instituto do Patrimônio Histórico e Artístico Nacional (IPHAN) e do Ministério da Cultura (MinC), a 
Capoeira foi reconhecida como Patrimônio Cultural Imaterial Brasileiro e no dia 26 de Novembro de 2014, a Organização das Nações Unidas para Educação, Ciência e Cultura (UNESCO) declarou a roda de capoeira como Patrimônio Cultural Imaterial da Humanidade. De acordo com a organização, a capoeira representa a luta e a resistência dos negros brasileiros contra a escravidão durante os períodos colonial e imperial de nossa história.

Essas ações constituem "uma resposta do Estado brasileiro às demandas sociais por reconhecimento e valorização de práticas culturais de matriz africana e indígena, secularmente excluídas das políticas públicas e que, por um longo período, foram vistas como um estorvo ao projeto civilizatório pautado na ideologia do branqueamento da sociedade nacional. Apenas recentemente, desde o início da década de 1990, em virtude da grande pressão exercida por segmentos da sociedade civil organizada, o Estado tem assumido a tarefa urgente de reverter o quadro da exclusão social de parcela expressiva da população do país (IPHAN, 2008, p.2-3)". Pensar em uma Museologia Afro-brasileira é atribuir uma perspectiva racial para as experiências e o conhecimento museológico, problematizando a presença (ou ausência) negra nos museus, do corpo de funcionários ${ }^{9}$ ao público visitante e/ou atuante, dos acervos aos projetos expográficos e, finalmente, dos discursos presentes nestas instituições.

\section{Diálogos entre a Museologia e a Capoeira}

A expectativa do desenvolvimento de uma Museologia Afrobrasileira, além de problematizar e enfatizar a presença (ou ausência) negra nos museus, também pode ser desenvolvida no âmbito da Museologia Social por meio da inclusão de demandas da população negra enquanto sociedade civil organizada - Movimento Negro.

${ }^{9}$ Com exceção aos profissionais contratados para a segurança dos museus, geralmente de empresas terceiradas. 
A Museologia Afro-brasileira pode então contribuir com a inclusão dos negros e negras nos espaços museológicos - e espaços culturais como um todo -, valorizando suas contribuições para a história, a cultura, a ciência, a economia e a política brasileiras, com a desconstrução de estereótipos e a promoção da igualdade de oportunidades, com a diminuição e eliminação de desigualdades e preconceitos acumulados historicamente, com a abolição das discriminações e com o combate ao genocídio da população negra brasileira. Para a construção dessa Museologia também faz-se necessário ir além da representatividade, ou seja, negros e negras devem estar presentes nos espaços museológicos, em sua concepção, definição de programas e estratégias educomunicativas e construção dos discursos museográficos, com ênfase às falas em primeira pessoa.

Podemos iniciar os diálogos entre a Museologia e a Capoeira direcionando um novo olhar, de forma positiva, para os negros brasileiros, e além disso, pensar na contribuição da Capoeira como Patrimônio Cultural Imaterial, reconhecendo sua importância na manutenção e preservação da cultura afro-brasileira, ou ainda como um objeto de estudos, enfatizando projetos que a usem como instrumento de cidadania e inclusão social.

Quando falamos da relação entre a Museologia Afro-brasileira e a Capoeira o acervo museológico não são os negros, mas a própria Capoeira, e seus representantes, linguagem corporal (gingado, golpes e esquivas), músicas, instrumentos musicais, aspectos linguísticos e oralidades, memórias, indumentárias etc., compõem as suas coleções. E em uma perspectiva de processo museológico de base comunitária, a gestão desse acervo deve ser desempenhada pelos próprios representantes da comunidade, no caso, integrantes do grupo de Capoeira, em um processo de apropriação e reapropriação desse patrimônio.

O registro dessas histórias, memórias, vivências (treinos, rodas de capoeira, batizados, participação em eventos e apresentações culturais), composições musicais, materialidades e identidades pode ser realizado de diversas formas, por meio da digitalização e/ou 
preservação desses documentos históricos em diferentes suportes (registros escritos, iconográficos, sonoros, visuais e audiovisuais).

A organização desse acervo facilita criação de linhas de pesquisa sobre os vários aspectos da Capoeira de forma geral, considerando suas diversas faces, ou seja, enquanto arte, dança, luta, jogo, esporte e cultura, e também estimula a alimentação permanente do acervo museológico do grupo.

Pensando na comunicação museológica, os aspectos museográficos e educativos podem ser desenvolvidos de diversas formas: podemos considerar treinos e rodas como exposições vivas da Capoeira; a promoção de exposições de longa-duração, temporárias e/ou itinerantes sobre os diversos aspectos da Capoeira e de especificidades dos grupos; ações culturais que facilitem a compreensão e promovam os diversos aspectos da Capoeira; a criação de websites e documentos audiovisuais (documentários) como recursos expográficos dos grupos, que atuariam como exposições de longa-duração, entre outras soluções criativas.

Esses aspectos da cadeia-operatória museológica evidenciam as possibilidades de diálogo entre a Museologia Afro-brasileira e a Capoeira, e muitos deles já são desenvolidos por diversos grupos em várias regiões do Brasil e do mundo.

Essas ações geralmente apresentam como objetivos gerais: promover prática da Capoeira, seu reconhecimento, valorização, preservação e divulgação como fenômeno cultural de origem afrobrasileira, portanto, de resistência; provocar reflexões e questionamentos sobre temas como Cultura Brasileira (e Afrobrasileira), Ancestralidade, Tradições Culturais, Identidade, Comunidade, Etnocentrismo e Preconceito; contribuir com o desenvolvimento social dos praticantes de Capoeira, alcançando diversas faixas etárias. Como objetivos específicos: divulgar Memórias, Histórias e Princípios Éticos relacionados à Capoeira, a partir de uma abordagem histórico-cultural, valorizando Mestres e Mestras que contribuíram para a sua preservação e difusão, desafios, lutas, conquistas etc.; valorizar e desenvolver as potencialidades dos indivíduos e coletivos, como a criatividade, a 
participação ativa, a iniciativa, a autorrealização, as capacidades perceptivas e físicas etc.; fomentar o respeito às diversidades dentro e fora da Capoeira; promover uma maior integração social entre os praticantes e o desenvolvimento social do território em que a Capoeira é praticada; estabelecer um vínculo entre os contextos sociais, as experiências individuais dos praticantes e a Capoeira etc. ${ }^{10}$

\section{Considerações Finais}

Considerando o contexto histórico da Capoeira como ponte facilitadora para a compreensão de seu desenvolvimento sociocultural, é indispensável ressaltar que, após muita luta, o reconhecimento buscado por vários Mestres/as de Capoeira vem sendo alcançado principalmente nas duas últimas décadas, mas não sem dificuldades e de maneira mais lenta do que o esperado, pois até os dias atuais é um ato de resistência estar inserida em muitos espaços de lazer, esporte e cultura.

Os diálogos estabelecidos com a Museologia Social, ou Museologia Afro-brasileira, e a Capoeira objetivam fortalecer esse processo histórico de resistência, ou seja, é um posicionamento estratégico, que possui uma concepção ampliada de Museu, compreendendo que este existe a partir do momento em que o grupo inicia um processo de autoreflexão sobre suas práticas, as compreende como um patrimônio cultural vivo e dinâmico e passa a relacionar estas práticas com os aspectos da cadeia operatória da museologia, desenvolvendo-os em seu âmbito. Dessa forma, o Museu e a Museologia são compreendidos como ferramentas que contribuem com a preservação e valorização das memórias, histórias e do acervo cultural da Capoeira, compreendidos como patrimônios culturais afro-brasileiros. Esse processo de preservação de memórias e práticas tem o potencial de contribuir, finalmente, para

10 Os objetivos apresentados neste parágrafo compõe o Projeto de Preservação de Memórias e Práticas do Grupo Capoeira E.C.E. Brasil, coordenado pelo Mestre Dinho Caruaru, e foi elaborado a partir da contribuição de vários e seus/suas integrantes. 
a formulação e promoção de políticas públicas de valorização e fomento desta prática cultural.

\section{Referências}

ALONSO FERNÁNDEZ, L. (1999). Introducción a la Nueva Museología. Madrid: Alianza Editorial.

BELLAIGUE, M. Uma nova visão do passado. (1993). Memória. São Paulo: Eletropaulo, v. 5, n. 19, 74-77. Entrevista concedida a Heloisa Barbuy.

CHAGAS, M. S.; GOUVEIA, I. (2014). Museologia Social: reflexões e práticas (à guisa de apresentação). Cadernos do CEOM Museologia Social. Chapecó: Unochapecó, Ano 27, n.41, 9-24 [Disponível

em https://bell.unochapeco.edu.br/revistas/index.php/rcc/issue/view/ 168/showToc, consultado em 02/02/2015].

DICIONÁRIO TUPI. (2017). Etnolinguística [Disponível em http://etnolinguistica.wdfiles.com/local--files/biblio\%3Abarbosa1951-pequeno/barbosa 1951 tupi-portugues.pdf, consultado em 15/10/2017].

FACURY, V. (2015). Mestre Bimba, Getúlio Vargas e a Capoeira [Disponível

em

https://www.thinglink.com/scene/669616632229789696, consultado em 10/10/2017].

FAUSTO, B. (2009). História do Brasil. São Paulo: Editora da Universidade de São Paulo - EDUSP.

FERREIRA, A. B. H. (1986). Novo dicionário da língua portuguesa. 2ª edição. Rio de Janeiro. Nova Fronteira.

GAMA, E.C. (2015). Kissimbiê: Águas do saber. Compreendendo a política de musealização como estratégia das comunidades-terreiro. In: 2ㅇ Simpósio Sudeste da ABHR, 2015, São Paulo. Anais do 20 Simpósio [...], vol.1 [Disponível em http://www.abhr.org.br/plura/ojs/index.php /anais/article/viewFile L1338/958, consultado em 24/04/2017]. 
IPHAN - Instituto do Patrimônio Histórico e Artístico Nacional. (2008). Registro da Capoeira como Patrimônio Cultural do Brasil. Salvador [Disponível em http://portal.iphan.gov.br/uploads /ckfinder/arquivos/Parecer\%20Capoeira.pdf, consultado em 16/02/2017].

LUSSAC, R. M. P. (2015). Especulações acerca das possíveis origens indígenas da capoeira e sobre as contribuições desta matriz cultural no desenvolvimento do jogo-luta. Revista Brasileira de Educação Física e Esporte. São Paulo: v. 29, 267-278 [Disponível em https://www.revistas.usp.br/rbefe/article/view/99800, consultado em 20/03/2018].

MESTRE WALDEMAR CONTEMPORÂNEO. (2013). Capoeira Contemporânea [Disponível em http://capoeiracontemporanea. blogspot.com.br/, consultado em 05/05/2018].

MOUTINHO, M. C. M. (1995). Museologia Informal. Boletim Associação Portuguesa de Museologia - APOM. Lisboa: APOM, série II, n.3, 22-24 [Disponível em http://www.minomicom.net/ old/signud/DOC\%20PDF/199501604.pdf, consultado em 17/02/2017.

NAVARRO, E. A. (2013). Dicionário de tupi antigo: a língua indígena clássica do Brasil. São Paulo: Global.

RIVARD, R. (1984). Nueva Museologia y Transformacion Social. In: Memoria del Seminario Territorio-Patrimonio-Comunidad (Ecomuseos) "El Hombre Y Su Entorno", Oaxtepec, Morelos, p.17-18, 63-69 [Disponível em http://www.minom-icom.net/ old/signud/ DOC\%20PDF/198403304.pdf, consultado em 10/03/2013].

SILVA, J. A. F. (2015). A Representação das Mulheres Negras nos Museus de Salvador: Uma Análise em Branco e Preto. 2015. Dissertação de Mestrado. Salvador: Programa de Pós-Graduação em Museologia da Universidade Federal da Bahia.

YRAPURU DZ, M. (2014). lêe... Vamos Embora (Estudos Cronológicos da Criação, Formação e Evolução da Capoeiragem 